\title{
Intestinal Ischemia-Reperfusion Increases Efflux for Uric Acid Via Paracellular Route in the Intestine, but Decreases that Via Transcellular Route Mediated by BCRP
}

\author{
Jiro Ogura ${ }^{1}$, Kaori Kuwayama ${ }^{1}$, Atsushi Takaya ${ }^{1}$, Yusuke Terada ${ }^{1}$, Takashi Tsujimoto ${ }^{1}$, Takahiro Koizumi ${ }^{1}$, Hajime \\ Maruyama $^{1}$, Asuka Fujikawa ${ }^{1}$, Natsuko Takahashi ${ }^{2}$, Masaki Kobayashi ${ }^{1}$, Shirou Itagaki ${ }^{1,3}$, Takeshi Hirano ${ }^{1,4}$, Hiroaki \\ Yamaguchi $^{1}$, Ken Iseki ${ }^{1}$ \\ ${ }^{1}$ Laboratory of Clinical Pharmaceutics \& Therapeutics, Division of Pharmasciences, Faculty of Pharmaceutical Sciences, \\ Hokkaido University Kita-12-jo, Nishi-6-chome, Kita-ku, Sapporo, Japan. \\ ${ }^{2}$ Graduate School of Medicine, Hokkaido University. \\ ${ }^{3}$ Present address: Department of Pharmacy, Hirosaki University School of Medicine \& Hospital, Hirosaki, Japan. \\ ${ }^{4}$ Present address: Department of Pharmacy, Kobe University Hospital, Kobe, Japan.
}

Received, November 8, 2011; Revised, March 23, 2012; Accepted, April 16, 2012; Published, April 18, 2012.

\begin{abstract}
Purpose. Uric acid is thought to be one of the most important antioxidants in human biological fluids. Intestinal ischemia-reperfusion $(\mathrm{I} / \mathrm{R})$ is an important factor associated with high rates of morbidity and mortality. Reactive oxygen species (ROS) are responsible for intestinal I/R injury. The aim of this study was to clarify the efflux for uric acid from the intestine after intestinal $I / R$. Methods. We used intestinal ischemia-reperfusion (I/R) model rats. Serosal to mucosal flux for $\left[{ }^{14} \mathrm{C}\right]$-uric acid was assessed by using Ussing-type diffusion chambers. BCRP/Bcrp expression was assessed by Western blot analysis. Caco-2 cells were used for a model of the intestinal epithelium, and rotenone was used as a mitochondrial dysfunction inducer. Results. Serosal to mucosal flux for uric acid was increased after intestinal $I / R$, and that for mannitol was also increased. Ko143, which is a BCRP inhibitor, did not affect the uric acid transport. The decreasing uric acid transport mediated by Bcrp was caused by decrease in the level of Bcrp homodimer, bridged by an S-S bond. The suppression of Bcrp S-S bond formation was associated with mitochondrial dysfunction. Moreover, BCRP S-S bond formation activity was decreased by rotenone in Caco-2 cells. Conclusions. Serosal to mucosal flux for uric acid is significantly increased via the paracelluler route, but that via the transcellular route mediated by Bcrp is decreased after intestinal I/R. The decreasing uric acid flux mediated by Bcrp is caused by suppression of Bcrp S-S bond formation. This suppression of Bcrp S-S bond formation may be related to mitochondrial dysfunction.
\end{abstract}

This article is open to POST-PUBLICATION REVIEW. Registered readers (see "For Readers") may comment by clicking on ABSTRACT on the issue's contents page.

\section{INTRODUCTION}

Intestinal ischemia-reperfusion $(\mathrm{I} / \mathrm{R})$ is a common clinical problem in small bowel transplantation, severe burn, circulatory shock and strangulation ileus. Intestinal $\mathrm{I} / \mathrm{R}$ is an important factor associated with high rates of morbidity and mortality (1). Interruption of blood supply results in ischemic injury, which rapidly damages metabolically active tissues. Paradoxically, restoration of blood flow to the ischemic tissue initiates a cascade of events that may lead to additional cell injury known as reperfusion injury. This reperfusion damage frequently exceeds the damage caused by the original ischemia insult (2). Reactive oxygen species (ROS) are responsible for intestinal $\mathrm{I} / \mathrm{R}$ injury $(3,4)$. Endogenous antioxidants and antioxidant enzymes may help in removing ROS and thus improving patients' clinical outcome $(4,5)$. Uric acid is the end product of purine metabolism generated from the breakdown of DNA, RNA and ATP.

Corresponding Author: Ken Iseki, Ph. D., Laboratory of Clinical Pharmaceutics \& Therapeutics, Division of Pharmasciences, Faculty of Pharmaceutical Sciences, Hokkaido University; Kita-12-jo, Nishi-6-chome, Kita-ku, Sapporo, Japan. E-mail: ken-i@pharm.hokudai.ac.jp 
Uric acid is recognized as a water-soluble antioxidant and is considered to be one of the most important antioxidants in human biological fluids $(6$, 7). Uric acid can donate an electron to form the urate radical and react with a variety of substances including hydrogen peroxide, hydroxyl radical, peroxynitrite and nitric oxide. This reactivity of uric acid might be beneficial for reducing oxidative stress. The gastrointestinal tract eliminates one-third of the uric acid (8). There are two efflux pathways that can function as compound secretion routes in the gastrointestinal tract $(9,10)$. One is the paracellular pathway to the lateral intercellular space via tight junctions between epithelial cells. This pathway is mainly a passive transport. The other efflux pathway is the transcellular pathway across the intestinal epithelial cell membrane. This pathway involves active transport mediated by transporters. Recently, breast cancer resistance protein (BCRP), the product of the ABCG2 gene, has been identified as an important efflux transporter of uric acid (11).

Compared with the molecular structures of P-glycoprotein (P-gp) and multidrug resistance-associated protein (MRP) families, BCRP is a so-called 'half-transporter'. BCRP protein is composed of 655 amino acids containing only one ATP-binding cassette and six transmembrane domains (12). Thus, it has been suspected that BCRP functions as an active homodimer, bridged by a disulfide (S-S) bond (13, 14). Cys-603 is an important residue in this S-S bond (15). Moreover, this S-S bond is necessary for the appropriate localization of BCRP (16). As mentioned above, BCRP S-S bond formation is an important factor for efflux of BCRP substrates.

In the present study, we investigated the serosal to mucosal flux for uric acid and Bcrp expression level, including Bcrp homodimer level, in the intestine after intestinal I/R. Moreover, we investigated the effect of mitochondrial dysfunction on suppression of BCRP S-S bond formation in Caco- 2 cells.

\section{MATERIALS AND METHODS}

\section{Chemicals}

$\left[{ }^{14} \mathrm{C}\right]$-Uric acid was purchased from MUROMACHI YAKUHIN KAISHA LTD. (Tokyo, Japan). D- $\left[{ }^{3} \mathrm{H}\right]$ mannitol was obtained from Perkin Elmer (Waltham, MA). Ko143 and rotenone were purchased from
SIGMA Aldrich (Tokyo, Japan). All other reagents were of the highest grade available and used without further purification.

\section{Animals}

Male Wistar rats, aged 6 weeks, were obtained from Jla (Tokyo, Japan). The rats were housed for at least 1 week at $23{ }^{\circ} \mathrm{C}$ and $60 \pm 10 \%$ relative humidity with a 12-h light/dark cycle (until reaching 250-350 g in weight). During the period of acclimatization, the rats were allowed free access to food and water. The experimental protocols were reviewed and approved by the Hokkaido University Animal Care Committee in accordance with the "Guide for the Care and Use of Laboratory Animals".

\section{Intestinal I/R model}

Surgical procedures were carried out as described in a previous report (17). The animals were anesthetized with sodium pentobarbital $(30 \mathrm{mg} / \mathrm{kg}$ body weight, i.p. injection). Through a midline laparotomy, each rat was subjected to $30 \mathrm{~min}$ of ischemia by ligating small anastomosing vessels and occluding the superior mesenteric artery (SMA). Reperfusion was induced by removing the clamp. The abdomen was then covered with a sterile plastic wrap. Rats were killed under surgical anesthesia at $1 \mathrm{~h}$ after reperfusion. Tissues were harvested just before killing.

\section{Cell culture}

Caco-2 cells obtained from RIKEN (Ibaraki, Japan) were maintained in plastic culture flasks (Corning Costar Corp., Cambridge, MA). These stock cells were subcultivated before reaching confluence. The medium consisted of Dulbecco's Modified Eagle's Medium (Sigma, Tokyo, Japan) supplemented with $10 \%$ fetal bovine serum (ICN Biomedicals, Inc, Aurora, $\mathrm{OH}$ ), 1\% nonessential amino acid (Gibco, Grand Island, NY), 2 mM L-glutamine (Gibco, Grand Island, NY) and $100 \mathrm{IU} / \mathrm{mL}$ penicillin- $100 \mathrm{mg} / \mathrm{mL}$ streptomycin (Sigma, Tokyo, Japan). Monolayer cultures were grown in an atmosphere of $5 \% \mathrm{CO}_{2}-95 \%$ air at $37^{\circ} \mathrm{C}$. The cells were given fresh growth medium every 2 days. When the Caco-2 cells had reached confluence, they were harvested with $0.25 \mathrm{mM}$ trypsin and $0.2 \%$ ethylene -diaminetetraacetic acid (EDTA) $\left(0.5-1 \mathrm{~min}\right.$ at $\left.37^{\circ} \mathrm{C}\right)$, resuspended, and seeded into a new flask. In the present study, Caco-2 cells were used between 
passages 45 and 60. Rotenone was dissolved in dimethyl sulfoxide (DMSO) $(<1 \% \quad \mathrm{w} / \mathrm{v}$ final concentration) and added to cells at various concentrations for a period of $3 \mathrm{~h}$.

\section{Transport experiments}

Transport experiments were carried out as described in a previous report (18). The intestine was quickly removed and the longitudinal muscle layer was carefully stripped off with scissors. Prepared intestinal sheets were filled with Hanks' balanced salt sodium (HBSS) buffer $(137 \mathrm{mM} \mathrm{NaCl}, 5.4 \mathrm{mM} \mathrm{KCl}$, $1.0 \mathrm{mM} \mathrm{CaCl}_{2}, 0.8 \mathrm{mM} \mathrm{MgCl}_{2}, 0.4 \mathrm{mM} \mathrm{KH}_{2} \mathrm{PO}_{4}, 0.3$ $\mathrm{mM} \mathrm{NaH} \mathrm{PO}_{4}$ and $25 \mathrm{mM}$ D-glucose). The $\mathrm{pH}$ of the buffer was adjusted to 6.0 or 7.4 with 4-(2-hydroxyethyl)-1-piperazineethanesulfonic acid (HEPES), 2-( $N$-morpholino)-ethanesulfonic acid (MES) or tris (hydroxymethyl)-aminomethane (Tris). The prepared intestinal sheets were mounted between two Ussing-type diffusion chambers (Corning Costar Corporation, Cambridge, Mass.) that provided an exposed area of $0.64 \mathrm{~cm}^{2}$. Considering the $\mathrm{pH}$ in the rat intestine in physiological condition (19), HBSS buffer was added to the chambers of the mucosal side $(\mathrm{pH}$ 6.0) and serosal side ( $\mathrm{pH}$ 7.4). The volume of bathing solution on each side was $1.0 \mathrm{~mL}$, and the solution temperature was maintained at $37^{\circ} \mathrm{C}$ in a water-jacketed reservoir. The solution was bubbled with a 95:5 mixture of $\mathrm{O}_{2} / \mathrm{CO}_{2}$ before and during the transport experiment. The buffer solution in the chambers of the serosal side contained a substrate. Samples of $0.25 \mathrm{~mL}$ were taken from the chambers of the mucosal side at $15,30,45$ and $60 \mathrm{~min}$ after incubation. A scintillation spectrometer (1600TR, Packard Instruments, Meriden, CT) was used to measure $\left[{ }^{14} \mathrm{C}\right]$-uric acid and $\left[{ }^{3} \mathrm{H}\right]$-mannitol.

The permeation rate of $\left[{ }^{14} \mathrm{C}\right]$-uric acid or $\mathrm{D}-\left[{ }^{3} \mathrm{H}\right]$-mannitol was expressed as an apparent permeability coefficient $\left(\mathrm{P}_{\text {app }}\right)$ according to the following equation: $\mathrm{P}_{\mathrm{app}}=\mathrm{d} Q / \mathrm{d} t / \mathrm{SC}_{0}$, where $\mathrm{d} Q / \mathrm{d} t$ is the linear appearance rate of mass in the receiver solution, $\mathrm{S}$ is the exposed area $\left(0.64 \mathrm{~cm}^{2}\right)$, and $\mathrm{C}_{0}$ is the initial concentration of $\left[{ }^{14} \mathrm{C}\right]$-uric acid $(10 \mu \mathrm{M})$ or $\mathrm{D}$ - $\left[{ }^{3} \mathrm{H}\right]$-mannitol $(50 \mathrm{nM}) . \quad \mathrm{P}_{\mathrm{app}}$ is expressed in centimeters per minute.

\section{Western blot analysis}

Total protein extracts were prepared from the ileal mucosa of rats or Caco- 2 cells. Ileal mucosa of rats or Caco-2 cells was suspended in lysis buffer containing
$1.0 \%$ Triton-X, $0.1 \%$ sodium dodecyl sulfate (SDS) and 4.5 $\mathrm{M}$ urea. The suspension was left to stand for $5 \mathrm{~min}$ and sonicated for $20 \mathrm{~min}$ at $4^{\circ} \mathrm{C}$. Then it was centrifuged at $12,100 \times \mathrm{g}$ for $15 \mathrm{~min}$ at $4^{\circ} \mathrm{C}$, and the protein concentrations of these samples in clear supernatant were determined by the method of Lowry et al. (20). The reducing conditions for samples of ileal mucosa in clear supernatant were as follows. The samples were denatured and reduced at $100^{\circ} \mathrm{C}$ for $5 \mathrm{~min}$ in a loading buffer containing $50 \mathrm{mM}$ Tris- $\mathrm{HCl}, 2 \%$ SDS, 5\% 2-mercaptoethanol, 10\% glycerol, $0.002 \%$ bromophenol blue (BPB) and $3.6 \mathrm{M}$ urea. The reducing conditions for samples of Caco-2 cells in clear supernatant were as follows. To the reducing reaction mixture containing $18 \mu \mathrm{L}$ of samples of Caco-2 cells in clear supernatant was added $2 \mu \mathrm{L}$ of $1 \mathrm{M}$ dithiothreitol (DTT). This mixture was incubated for $2 \mathrm{~h}$ at $37^{\circ} \mathrm{C}$ and then $4.8 \mu \mathrm{L}$ of $1 \mathrm{M}$ iodoacetamide was added. The mixture was incubated for $30 \mathrm{~min}$ at $37^{\circ} \mathrm{C}$. After adding $4 \mu \mathrm{L}$ of $200 \mathrm{mM} \mathrm{NaOH}$, the mixture was cooled with tap water. These samples of Caco-2 cells were denatured at $100^{\circ} \mathrm{C}$ for $5 \mathrm{~min}$ in a loading buffer containing 50 $\mathrm{mM}$ Tris- $\mathrm{HCl}, 12.5 \%$ SDS, 20\% 2-mercaptoethanol, $10 \%$ glycerol, $100 \mathrm{mM}$ DTT, $5 \mathrm{mM}$ sodium bisulfite, $0.002 \% \mathrm{BPB}$ and $3.6 \mathrm{M}$ urea. The non-reducing conditions for samples of Caco-2 cells or ileal mucosa were as follows. The samples were denatured at room temperature for $5 \mathrm{~min}$ in loading buffer containing $50 \mathrm{mM}$ Tris- $\mathrm{HCl}, 2 \% \mathrm{SDS}, 10 \%$ glycerol, $0.002 \% \mathrm{BPB}$ and $3.6 \mathrm{M}$ urea. Each sample was separated on $4.5 \%$ stacking and $10 \%$ SDS polyacrylamide gels. Proteins were transferred electrophoretically onto nitrocellulose membranes at $15 \mathrm{~V}$ for $90 \mathrm{~min}$. The membranes were blocked with PBS containing $0.05 \%$ Tween 20 (PBS/T) and 10\% non-fat dry milk for $1 \mathrm{~h}$ at room temperature. After being washed with $\mathrm{PBS} / \mathrm{T}$, the membranes were incubated overnight at room temperature with a mouse monoclonal antibody to BXP-21 (Santa Cruz Biotechnology, Santa Cruz, CA) at a dilution of 1:250 and washed three times with PBS/T for 10 min each time. The membranes were subsequently incubated for $1 \mathrm{~h}$ at room temperature with horseradish peroxidase-conjugated goat anti-mouse secondary antibody (Santa Cruz Biotechnology, Santa Cruz, CA) at a dilution of 1:2,000 and washed three times with $\mathrm{PBS} / \mathrm{T}$ for $10 \mathrm{~min}$ each time. The bands were visualized by enhanced chemiluminescence according to the instructions of the manufacturer 
(Amersham Biosciences Corp., Piscataway, NJ).

\section{MTT assay (in vivo)}

Mucosal cellular mitochondrial dehydrogenase activity was examined by measuring the mitochondrial dehydrogenase-dependent reduction of 3-(4,5-dimethylthiazol-2-yl)-2,5-diphenyltetrazolium bromide (MTT) to its formazan derivative (MTT-FZ). This method was carried out as described in a previous report with some modification $(21,22)$. At $30 \mathrm{~min}$ before the end of the reperfusion period, a 5 -cm-long segment of the ileum was identified and ligated at both ends. Then 1\% MTT, dissolved in physiological saline, was put into the lumen. After intestinal $\mathrm{I} / \mathrm{R}, 10 \mathrm{~mL}$ of cold physiological saline was used to wash out the remaining MTT solution from the ileal segment. The segment was opened and the mucosal layer was collected and homogenized in 3 $\mathrm{mL}$ of cold PBS. The tissue homogenate, 0.25 or 0.5 $\mathrm{mL}$, was transferred into two Eppendorf tubes (to be used for the MTT-FZ assay or DNA assay). After centrifugation again $\left(2,500 \times \mathrm{g}\right.$ for $10 \mathrm{~min}$ at $\left.4^{\circ} \mathrm{C}\right)$, the pellet was washed with $1.5 \mathrm{~mL}$ of PBS. After centrifugation $\left(9,200 \times \mathrm{g}\right.$ for $10 \mathrm{~min}$ at $\left.4^{\circ} \mathrm{C}\right)$, MTT-FZ contained in the mucosal cells was solubilized with 2 $\mathrm{mL}$ of dimethyl sulfoxide. The aliquots were sonicated for $30 \mathrm{~min}$ at $4^{\circ} \mathrm{C}$ and centrifuged at $9,200 \times \mathrm{g}$ for $10 \mathrm{~min}$ at $4^{\circ} \mathrm{C}$. Then $0.2 \mathrm{~mL}$ of supernatant was drawn out and placed into a 96-well plastic plate and its absorbance was determined at $590 \mathrm{~nm}$ by a spectrophotometer. Total DNA was determined by a diphenylamine reaction. The tissue homogenate was centrifuged at $2,500 \times \mathrm{g}$ for $10 \mathrm{~min}$ at $4^{\circ} \mathrm{C}$ and then washed with $1.5 \mathrm{~mL}$ of PBS. After centrifugation again $\left(9,200 \times \mathrm{g}\right.$ for $10 \mathrm{~min}$ at $\left.4^{\circ} \mathrm{C}\right), 0.5$ $\mathrm{mL}$ of lysis buffer ( $\mathrm{pH} 8.0$ ) consisting of $5 \mathrm{mM}$ Tris-HCl, $20 \mathrm{mM}$ EDTA, and $0.5 \%$ (wt/vol) Triton $\mathrm{X}-100$ was added to the pellet. Dische reaction mixture consisted of $0.25 \mathrm{~mL}$ of suspension and 2.5 $\mathrm{mL}$ Dische reagent. The Dische reagent was acetic acid solution consisting of $1 \%$ diphenylamine and $2 \%$ sulfuric acid. The Dische reaction mixture was heated at $100^{\circ} \mathrm{C}$ for $5 \mathrm{~min}$. After cooling with tap water, the absorbance was measured at $590 \mathrm{~nm}$. The results were expressed as ratio of MTT-FZ to DNA absorbance.

\section{MTT assay (in vitro)}

The MTT assay was performed as described previously with a certain modification (23). Various concentrations of rotenone were added for $3 \mathrm{~h}$. At 60 min before the end of treatment, $10 \mu \mathrm{L}$ of PBS-containing MTT solution $(0.5 \%)$ was added, and the cells were incubated for a further $60 \mathrm{~min}$. The MTT medium was then replaced with $0.2 \mathrm{~mL}$ DMSO and absorbance was read at $590 \mathrm{~nm}$. Absorbance measured in MTT assays was expressed as percent of the control (defined as $100 \%$ ).

\section{Trypan blue staining}

After washing with PBS, Caco-2 cells were harvested with $0.25 \mathrm{mM}$ trypsin and $0.2 \%$ EDTA $(0.5-1 \mathrm{~min}$ at $37^{\circ} \mathrm{C}$ ). After washing with PBS again, the cells were incubated with $0.05 \%$ trypan blue stain in PBS for 3 min at room temperature and diluted in PBS (1:20). After centrifugation $\left(9,200 \times \mathrm{g}\right.$ for $5 \mathrm{~min}$ at $\left.20^{\circ} \mathrm{C}\right)$, the cells were suspended in $1.5 \mathrm{~mL}$ of PBS. Counting was done using a Nikon photomicroscope.

\section{Quantitative real-time PCR}

Total RNA was prepared from Caco-2 cells using an ISOGEN (Nippon Gene, Tokyo) and an RNase-Free DNase Set (QIAGEN, Tokyo, Japan). Single-strand cDNA was made from $2 \mu \mathrm{g}$ total RNA by reverse transcription using a ReverTra Ace (TOYOBO, Osaka, Japan). Quantitative real-time PCR was performed using an ABI PRISM 7700 sequence Detector (Applied Biosystems, Foster City, CA) with Platinum $^{\circledR}$ SYBR $^{\circledR}$ Green qPCR SuperMix-UDG (Invitrogen, Carlsbad, CA) as per the manufacturer's protocol. PCR was performed using human BCRP-specific primers through 40 cycles of $95^{\circ} \mathrm{C}$ for $15 \mathrm{~s}, 52^{\circ} \mathrm{C}$ for $30 \mathrm{~s}$ and $72^{\circ} \mathrm{C}$ for $30 \mathrm{~s}$. The primers specific to human BCRP and GAPDH were designed on the basis of sequences in GenBankTM database (accession no.: NM_004827 and NM_002046, respectively). The sequences of the specific primers were as follows: the sense sequence (1038-1057) was 5'-TTA TCC GTG GTG TGT CTG GA-3' and the antisense sequence (1261-1280) was 5'-TTC CTG AGG CCA ATA AGG TG-3' for human BCRP, and the sense sequence (757-776) was 5'-AAG GTC ATC CCT GAG CTG AA-3' and the antisense sequence (833-852) was 5'-TTC TAG ACG GCA GGT CAG GT-3' for human GAPDH. The PCR products were normalized to amplified GAPDH, which was the internal reference gene (housekeeping gene). Standard curves were prepared for each target and housekeeping gene. The standard curve was established between the threshold cycles $(\mathrm{Ct})$ and the 
$\log _{10}$ (copy numbers) by using the Applied Biosystems sequence detection system software, version 1.9.1. The software calculates the relative amount of the target gene and the housekeeping gene based on the $\mathrm{Ct}$.

\section{Immunocytochemistry}

Caco-2 cells were fixed in methanol for 15 minutes at $-10^{\circ} \mathrm{C}$. The cells were first incubated in a blocking buffer (10\% FBS in PBS) for $60 \mathrm{~min}$. Then the cells were incubated overnight at room temperature with BXP-21 (dilution of 1:50). The cells were subsequently incubated for $1 \mathrm{~h}$ at $37^{\circ} \mathrm{C}$ with rhodamine-conjugated donkey anti-mouse secondary antibody (Santa Cruz Biotechnology) at a dilution of 1:400. Nuclei were stained with 4', 6-diamidino-2-phenylindole (DAPI) and the cells were mounted in VECTASHIELD Mounting Medium (Vector Laboratories, Burlingame, CA). The localization of BCRP was visualized by using a confocal microscope (Zeiss LSM-510; Carl Zeiss Inc., Thornwood, NY).

\section{DATA ANALYSIS}

Statistical significance was evaluated using one-way analysis of variance unpaired Student's $t$-test (MTT assay in vivo), Duncan's test (transport experiments) or Dunnett's test (in vitro experiments). A value of $\mathrm{p}<0.05$ was considered significant.

\section{RESULTS}

Serosal to mucosal flux for uric acid in the intestine after intestinal $\mathbf{I} / \mathbf{R}$

Serosal to mucosal flux for uric acid was calculated from the linear mucosal radioisotope appearance curves. Paracellular transport was assessed by serosal to mucosal flux for mannitol. $\mathrm{P}_{\text {app }}$ of uric acid after intestinal $\mathrm{I} / \mathrm{R}$ was significantly higher than that of sham-operated rats (Fig. 1A). $\mathrm{P}_{\text {app }}$ of mannitol was also significantly higher (Fig. 1B). However, Ko143, which is a BCRP inhibitor, did not affect $\mathrm{P}_{\text {app }}$ of uric acid after intestinal I/R (Fig. 1A). These results indicated that serosal to mucosal flux for uric acid was increased by inducing paracellular transport but that serosal to mucosal flux for uric acid via the transcellular route mediated by Bcrp was decreased.

\section{Bcrp expression and homodimer level after intestinal $\mathbf{I} / \mathbf{R}$}

Next, we assessed the effect of intestinal I/R on Bcrp total protein expression and homodimer, bridged by an S-S bond, levels. The total expression of Bcrp in the intestine was not altered after intestinal I/R (Fig. 2A). The level of Bcrp homodimer, bridged by an S-S bond, was decreased after intestinal I/R (Fig. 2B). This result was associated with the inhibitory effect of Ko143 on uric acid transport after intestinal I/R.

\section{Mitochondrial function after intestinal I/R}

An S-S bond of proteins is known to be formed by reductive/oxidative reaction. Since the redox status of cells is related to mitochondrial function, we speculated that mitochondrial dysfunction affected the Bcrp S-S bond formation after intestinal I/R. Mitochondrial function was suppressed at $1 \mathrm{~h}$ after intestinal I/R (Fig. 3). Since this result was associated with the suppression of Bcrp S-S bond formation, we determined that mitochondrial dysfunction might cause the suppression of Bcrp S-S bond formation.

\section{Effect of rotenone on BCRP expression in Caco-2 cells}

We investigated whether mitochondrial dysfunction affected BCRP S-S bond formation in Caco-2 cells using rotenone, which is a mitochondrial dysfunction inducer. Mitochondrial function was suppressed by 1-10 $\mu \mathrm{M}$ rotenone (Fig. 4A). In contrast, cell viability was not altered by $0.5-10 \mu \mathrm{M}$ rotenone (Fig. 4B). These results indicated that rotenone induced mitochondrial dysfunction without decrease in cell viability. Next, we assessed the effect of rotenone on BCRP mRNA, total protein expression and homodimer, bridged by an S-S bond, level in Caco-2 cells. The mRNA level of BCRP was not altered by 0.5-10 $\mu \mathrm{M}$ rotenone (Fig. 5A). The total expression of BCRP was also not altered by $0.5-10 \mu \mathrm{M}$ rotenone (Fig. 5B). The BCRP homodimer, bridged by an S-S bond, level was decreased by rotenone (Fig. 5C).

These results indicated that rotenone suppressed S-S bond formation of BCRP but did not affect mRNA and total protein expression. Takada et al. reported that formation of a homodimer bridged by an S-S bond at Cys603 was necessary for membrane localization of BCRP (16). 
(A) Serosal to mucosal flux for uric acid

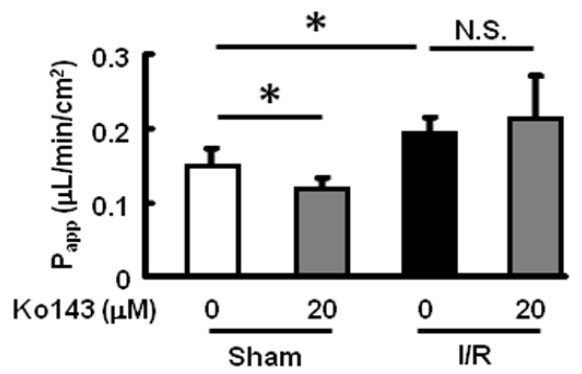

(B) Serosal to mucosal flux for mannitol

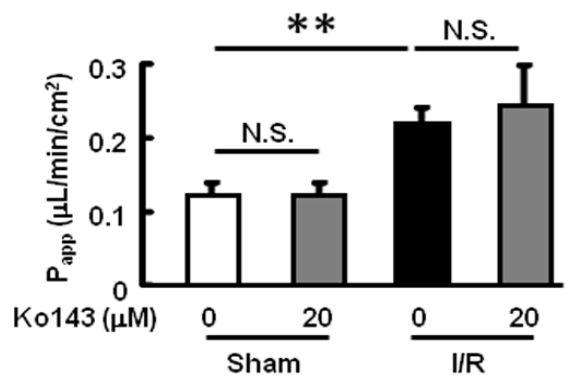

Figure 1. Serosal to mucosal flux for uric acid and mannitol in the intestine after intestinal $\mathrm{I} / \mathrm{R}$. (A) $\mathrm{P}_{\text {app }}$ of $\left[{ }^{14} \mathrm{C}\right]$-uric acid across the intestinal membrane. (B) $\mathrm{P}_{\text {app }}$ of $\mathrm{D}-\left[{ }^{3} \mathrm{H}\right]$-mannitol across the intestinal membrane. The buffer was adjusted to pH 6.0 and 7.4 on the mucosal and serosal sides, respectively. The temperature was maintained at $37^{\circ} \mathrm{C}$. The buffer on the serosal side contained $10 \mu \mathrm{M}\left[{ }^{14} \mathrm{C}\right]$-uric acid and $50 \mathrm{nM} \mathrm{D}-\left[{ }^{3} \mathrm{H}\right]$-mannitol. Each column represents the mean with S.D. of 5-9 measurements. *; $\mathrm{P}<0.05$ significantly different from sham. **; $\mathrm{P}<0.01$. N.S.; not significant.
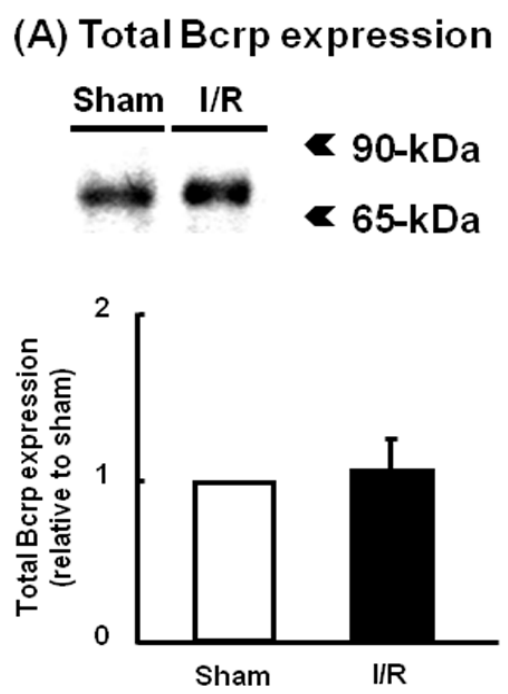

(B) Bcrp dimer level
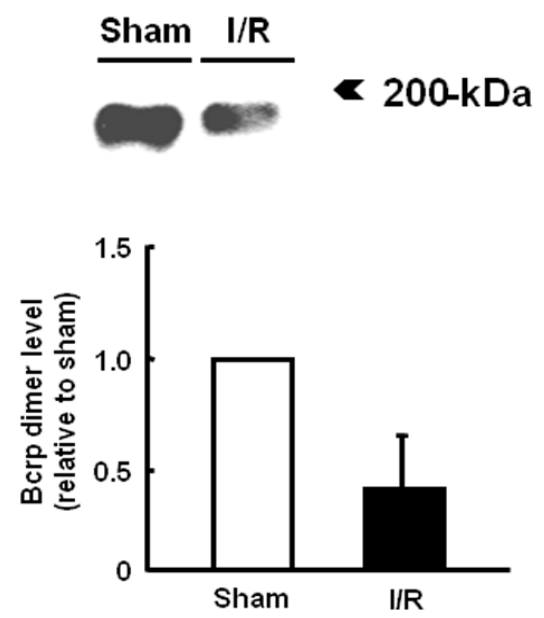

Figure 2. Bcrp protein expression in the ileum after intestinal I/R. (A) Analysis of total Bcrp protein expression by Western blot analysis under reducing condition. (B) Analysis of Bcrp dimer level by Western blot analysis under non-reducing condition. Whole cell lysates of the ileum at $1 \mathrm{~h}$ after intestinal $\mathrm{I} / \mathrm{R}$ were used as samples for Western blot analysis. The intensity of Western blot analysis was determined by densitometry using Scion image program. Each column represents the mean with S.D. of 3-4 measurements.

Based on this finding, we investigated whether the suppression of BCRP $\mathrm{S}-\mathrm{S}$ bond formation by rotenone caused a decrease in BCRP expression at the membrane. BCRP was retained near the nuclei by rotenone (Fig. 6).

\section{DISCUSSION}

The purpose of this study was to clarify the efflux of uric acid from the intestine and the alteration in the expression of Bcrp, which is an uric acid efflux transporter, after intestinal I/R.
Serosal to mucosal flux for uric acid was significantly increased after intestinal I/R (Fig. 1A). It is well known that intestinal $I / R$ decreases basement membrane integrity and decreases barrier function (2). In fact, we previously reported that the TEER value of the intestinal membrane in intestinal $\mathrm{I} / \mathrm{R}$ rats was significantly decreased compared with that in sham-operated rats (18). Therefore, we speculated that serosal to mucosal flux for uric acid after intestinal $\mathrm{I} / \mathrm{R}$ might be caused by inducing paracellular transport. 


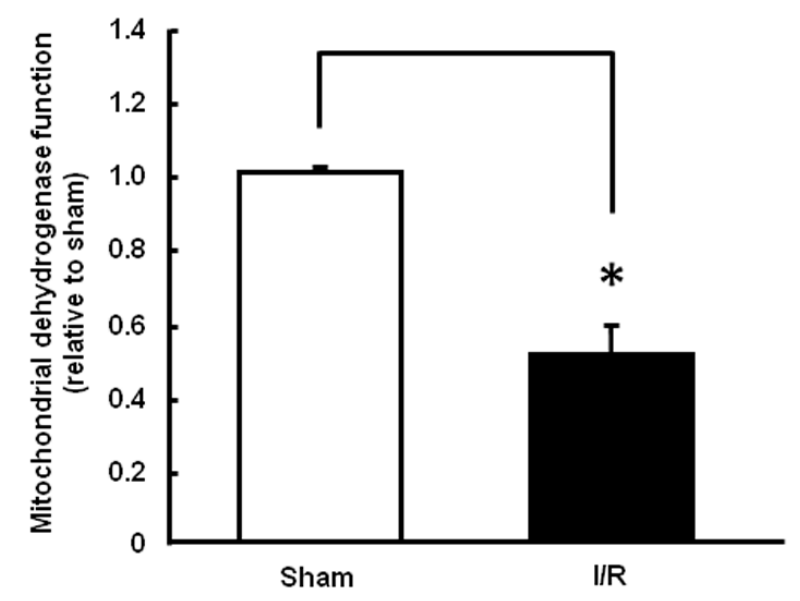

Figure 3. Mitochondrial function in the ileum after intestinal I/R. Mitochondrial function was assessed by MTT assay. Each column represents the mean with S.D. of 3 measurements. *; $\mathrm{P}<0.05$ significantly different from sham.

(A) Mitochondrial function

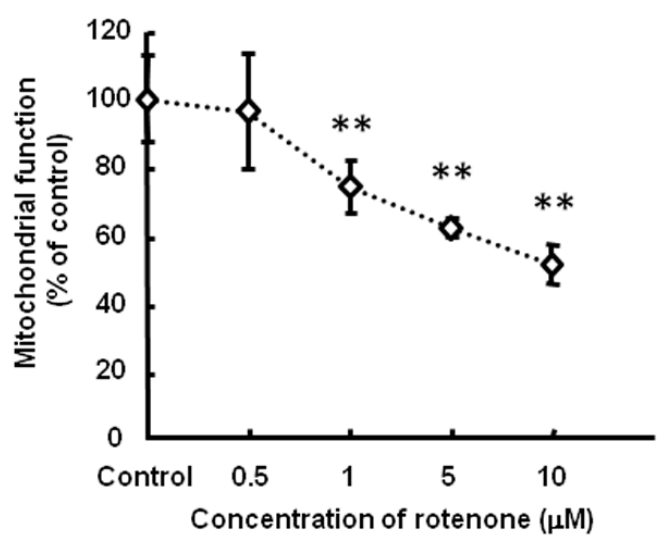

(B) Cell viability

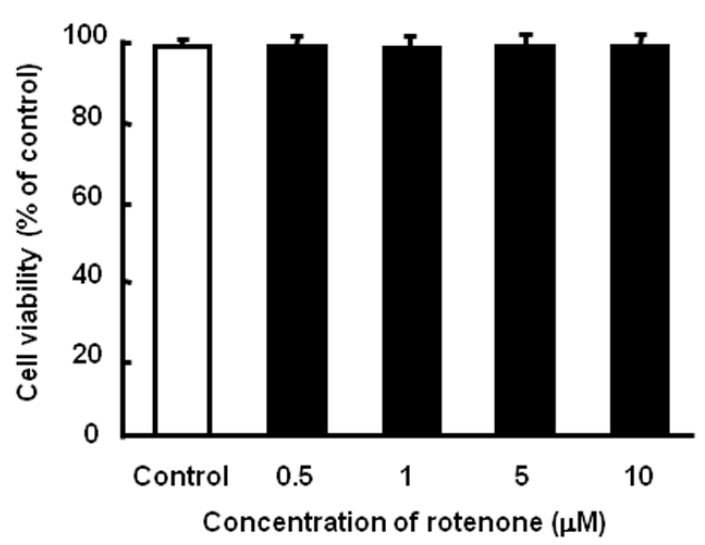

Figure 4. Effects of rotenone on mitochondrial function and cell viability. (A) Mitochondrial dehydrogenase activity was measured by MTT assay. Each point represents the mean with S.D. of 7 measurements. (B) Cell viability was assessed by trypan blue staining. Each column represents the mean with S.D. of 3 measurements. Caco-2 cells were exposed to various concentrations of rotenone for $3 \mathrm{~h}$. Control was incubated in a medium for $3 \mathrm{~h}$. $* * ; \mathrm{P}<0.01$ significantly different from the control.

Serosal to mucosal flux for mannitol, as well as that for uric acid, was significantly increased (Fig. 1B). BCRP is known to be an important efflux transporter for uric acid. Thus, we investigated the serosal to mucosal flux for uric acid via Bcrp using Ko143, which is a BCRP inhibitor. Ko143 did not affect the serosal to mucosal flux for uric acid after intestinal I/R (Fig. 1A). Moreover, Bcrp homodimer, bridged by an S-S bond, level was decreased (Fig. 2B), though Bcrp total expression was not altered after intestinal I/R (Fig. 2A).

These results indicated that serosal to mucosal flux for uric acid was increased by inducing paracellular transport but that serosal to mucosal flux for uric acid via transcelluar transport mediated by Bcrp was decreased. Uric acid is thought to be one of the most important antioxidants in the plasma. Therefore, maintenance of uric acid level is important for protection against oxidative stress after intestinal $\mathrm{I} / \mathrm{R}$. However, uric acid leaked into the lateral intercellular space via tight junctions between epithelial cells because the tight junctions in the intestine were damaged after intestinal $I / R$ (18). The decreasing efflux for uric acid via the transcellular route mediated by Bcrp reduced leakage of uric acid. 
(A) mRNA level

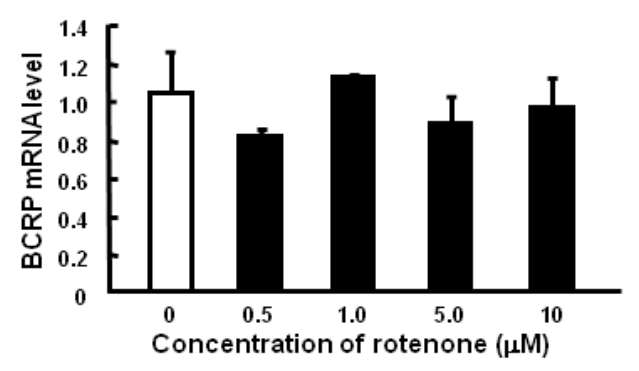

(C) BCRP dimer level
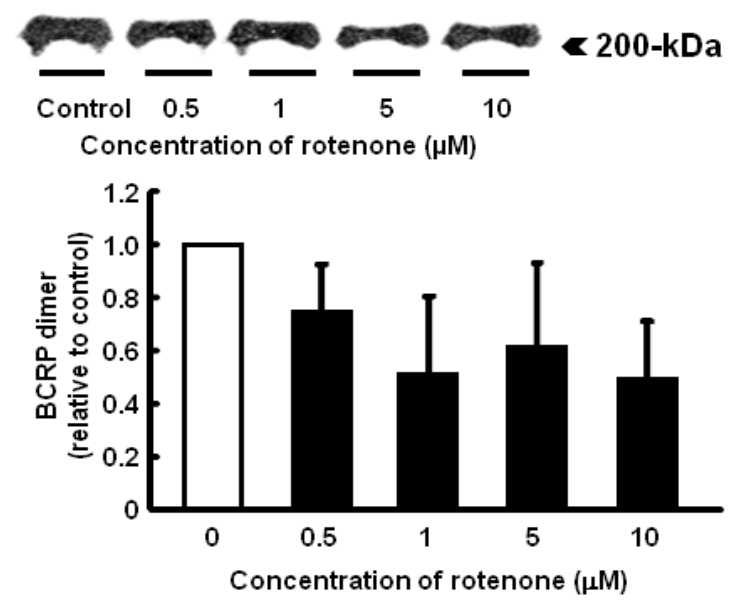

(B) Total BCRP expression
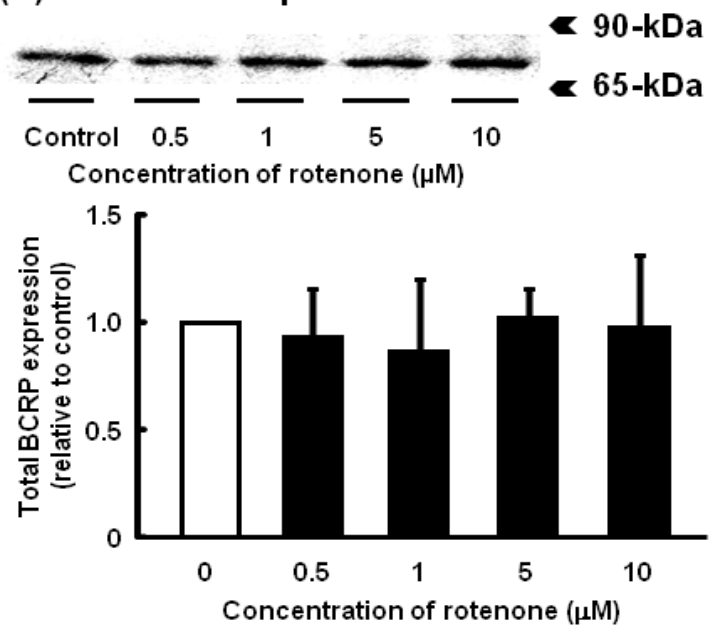

Figure 5. Effect of rotenone on BCRP expression. (A) Measurement of BCRP mRNA level by real-time PCR. Caco-2 cells were exposed to rotenone for $3 \mathrm{~h}$. Control was incubated in a medium for $3 \mathrm{~h}$. Each column represents the mean with S.D. of 3 measurements. (B) Analysis of total BCRP protein expression by Western blot analysis under reducing condition. Caco-2 cells were exposed to rotenone for $3 \mathrm{~h}$. Control was incubated in a medium for $3 \mathrm{~h}$. Caco-2 cell lysates were used as samples for Western blot analysis. The intensity of Western blot analysis was determined by densitometry using Scion image program. Each column represents the mean with S.D. of 5 measurements. (C) Analysis of BCRP dimer level by Western blot analysis under non-reducing condition. Caco-2 cells were exposed to rotenone for $3 \mathrm{~h}$. Control was incubated in a medium for $3 \mathrm{~h}$. Caco-2 cell lysates were used as samples for Western blot analysis. The intensity of Western blot analysis was determined by densitometry using Scion image program. Each column represents the mean with S.D. of 5 measurements.

An S-S bond of proteins is known to be formed by reductive/oxidative reaction. Since the redox status of cells is related to mitochondrial function, we speculated that mitochondrial dysfunction affected Bcrp S-S bond formation after intestinal I/R. Mitochondrial function was significantly suppressed after intestinal I/R (Fig. 3), as well as Bcrp S-S bond formation. This result suggested that mitochondrial dysfunction caused the suppression of Bcrp S-S bond formation. It is known that formation of a homodimer, bridged by an S-S bond, is necessary for membrane localization of BCRP (16).

We previously reported that Bcrp expression level in the apical membrane in the ileum after intestinal I/R was significantly decreased (25). These findings suggest that the decrease in BCRP expression at the apical membrane after intestinal $\mathrm{I} / \mathrm{R}$ is caused by suppression of BCRP S-S bond formation.

Next, we investigated the details of the relation between mitochondrial dysfunction and suppression of BCRP S-S bond formation using Caco-2 cells, as a model of the human intestinal epithelium. It is known that rotenone induces mitochondrial dysfunction by interfering with the electron transport chain in mitochondria. Rotenone was found to inhibit mitochondrial function in a concentration-dependent manner (Fig. 4A), but cell viability was not affected by $10 \mu \mathrm{M}$ rotenone (Fig. $4 \mathrm{~B}$ ). On the basis of these results, we used rotenone as a mitochondrial dysfunction inducer in this study. 


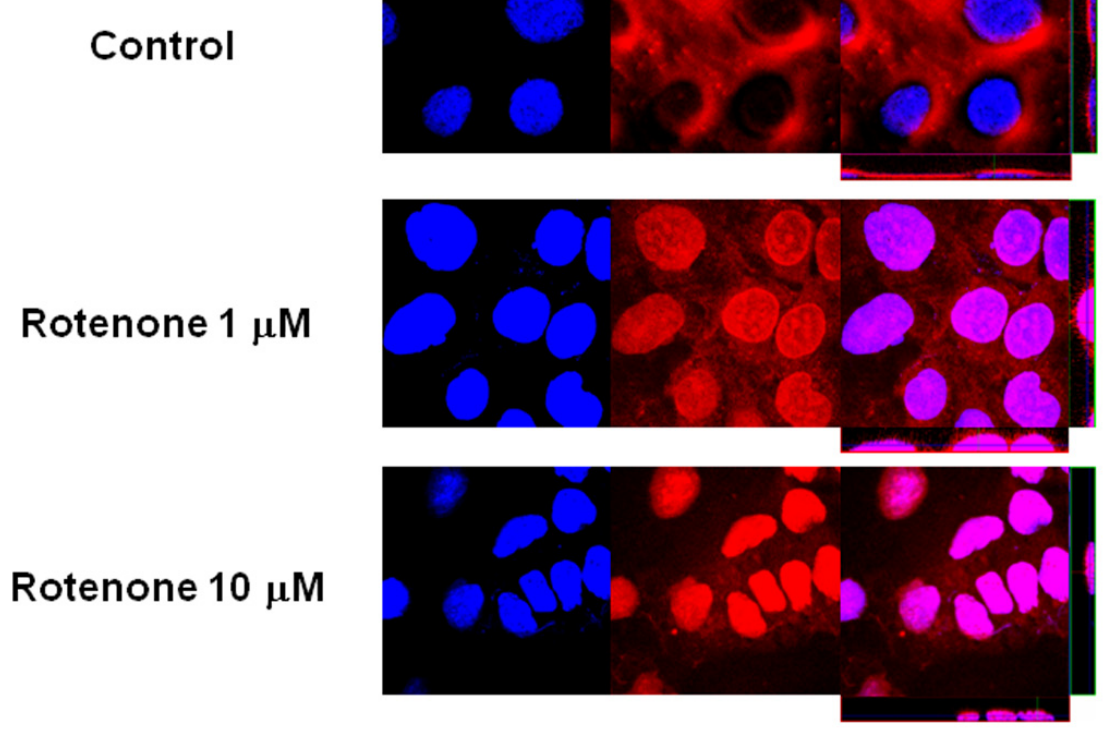

Figure 6. Effect of totenone on BCRP expression in the Caco- 2 membrane. Caco- 2 cells were exposed to 1 or $10 \mu \mathrm{M}$ rotenone. Control was incubated in a medium for $3 \mathrm{~h}$. Localization of BCRP was determined by using an anti-BCRP antibody (red). Nuclei were stained with DAPI (blue).

The BCRP homodimer, bridged by an S-S bond, level was significantly reduced by rotenone (Fig. 5C), but mRNA level (Fig. 5A) and total expression of BCRP protein (Fig. 5B) were not altered. These results indicated that mitochondrial dysfunction caused the suppression of BCRP S-S bond formation. Moreover, rotenone decreased the expression of BCRP in the Caco-2 membrane (Fig. 6). This result suggested that the suppression of BCRP S-S bond formation by mitochondrial dysfunction was associated with the decrease in BCRP expression at the membrane.

The molecular masses of human BCRP and rat Bcrp are known to be 72 and $62 \mathrm{kDa}$, respectively. All of the BCRP/Bcrp protein was able to be detected as a monomer by SDS-PAGE under reducing condition (Supplementary fig. 1). On the other hand, human BCRP or rat Bcrp migrated as a $200-\mathrm{kDa}$ protein or a $\sim 200-\mathrm{kDa}$ protein by SDS-PAGE under non-reducing condition (Supplementary fig. 1). Hori et al. reported that rat Bcrp homodimer was detected as a $\sim 170-\mathrm{kDa}$ protein, because Bcrp homodimer was modified by N-linked glycosylation (26). In accordance with their finding, human BCRP homodimer and rat Bcrp homodimer were detected as a $200-\mathrm{kDa}$ protein, not as a $144-\mathrm{kDa}$ protein, and as a $\sim 200-\mathrm{kDa}$ protein, not as a $124-\mathrm{kDa}$ protein.

In conclusion, serosal to mucosal flux for uric acid is significantly increased via the paracellular route, but that via Bcrp is decreased after intestinal $\mathrm{I} / \mathrm{R}$. The decreasing uric acid flux via Bcrp is caused by suppression of Bcrp S-S bond formation. This suppression of Bcrp S-S bond formation may be related to mitochondrial dysfunction.

\section{ACKNOWLEDGEMENT}

This work was supported in part by Grant-in-Aid for Research Activity start-up.

\section{REFERENCES}

1. Koike K, Moore FA, Moore EE, Read RA, Carl VS, Banerjee A. Gut ischemia mediates lung injury by a xanthine oxidase-dependent neutrophil mechanism. J Surg Res, 1993; 54:469-73.

2. Kong SE, Blennerhassett LR, Heel KA, McCauley RD, Hall JC. Ischaemia-reperfusion injury to the intestine. Aust N Z J Surg, 1998; 68:554-61.

3. Parks DA, Bulkley GB, Granger DN, Hamilton SR, McCord JM. Ischemic injury in the cat small intestine: role of superoxide radicals. Gastroenterology, 1982; 82:9-15.

4. Schoenberg MH, Beger HG. Oxygen radicals in intestinal ischemia and reperfusion. Chem Biol Interact, 1990; 76:141-61.

5. Ceran C, Sönmez K, Türkyllmaz Z, Demirogullarl B, Dursun A, Düzgün E, Başaklar AC, Kale N. Effect of bilirubin in ischemia/reperfusion injury on rat small 
intestine. J Pediatr Surg, 2001; 36:1764-7.

6. Ames BN, Cathcart R, Schwiers E, Hochstein P. Uric acid provides an antioxidant defense in humans against oxidant- and radical-caused aging and cancer: a hypothesis. Proc Natl Acad Sci U S A, 1981; 78:6858-62.

7. Becker BF. Towards the physiological function of uric acid. Free Radic Biol Med, 1993; 14:615-31.

8. Hediger MA, Johnson RJ, Miyazaki H, Endou H. Molecular physiology of urate transport. Physiology (Bethesda), 2005; 20:125-33.

9. Hayashi M, Tomita M. Transcellular and paracellular contribution to transport processes in the colorectal route. Adv Drug Deliv Rev, 1997; 28:191-204.

10. Hayashi M, Tomita M. Mechanistic analysis for drug permeation through intestinal membrane. Drug Metab Pharmacokinet, 2007; 22:67-77.

11. Woodward OM, Kottgen A, Coresh J, Boerwinkle E, Guggino WB, Kottgen M. Identification of a urate transporter, ABCG2, with a common functional polymorphism causing gout. Proc Natl Acad Sci U S A, 2009; 106:10338-42.

12. Mao Q, Unadkat JD. Role of the breast cancer resistance protein $(\mathrm{ABCG} 2)$ in drug transport. AAPS J, 2005; 7:E118-33.

13. Kage K, Tsukahara S, Sugiyama T, Asada S, Ishikawa E, Tsuruo T, Sugimoto Y. Dominant-negative inhibition of breast cancer resistance protein as drug efflux pump through the inhibition of S-S dependent homodimerization. Int J Cancer, 2002; 97:626-30.

14. Litman T, Jensen U, Hansen A, Covitz KM, Zhan Z, Fetsch P, Abati A, Hansen PR, Horn T, Skovsgaard T, Bates SE. Use of peptide antibodies to probe for the mitoxantrone resistance-associated protein MXR/BCRP/ABCP/ABCG2. Biochim Biophys Acta, 2002; 1565:6-16.

15. Kage K, Fujita T, Sugimoto Y. Role of Cys-603 in dimer/oligomer formation of the breast cancer resistance protein BCRP/ABCG2. Cancer Sci, 2005; 96:866-72.

16. Takada T, Suzuki H, Sugiyama Y. Characterization of polarized expression of point- or deletion-mutated human BCRP/ABCG2 in LLC-PK1 cells. Pharm Res, $2005 ; 22: 458-464$.

17. Ogura J, Kobayashi M, Itagaki S, Hirano T, Iseki K. Alteration of Mrp2 and P-gp expression, including expression in remote organs, after intestinal ischemia-reperfusion. Life Sci, 2008; 82:1242-8.
18. Ogura J, Maruyama H, Kobayashi M, Itagaki S, Iseki K. Pharmacokinetics of oral and intravenous administration of digoxin after intestinal ischemia-reperfusion. Biol Pharm Bull, 2010; 33:922-5.

19. McConnell EL, Basit AW, Murdan S. Measurements of rat and mouse gastrointestinal $\mathrm{pH}$, fluid and lymphoid tissue, and implications for in-vivo experiments. J Pharm Pharmacol, 2008; 60:63-70.

20. Lowry $\mathrm{OH}$, Rosebrough NJ, Farr AL, Randall RJ. Protein measurement with the Folin phenol reagent. J Biol Chem, 1951; 193:265-75.

21. Unno N, Wang H, Menconi MJ, Tytgat SH, Larkin V, Smith M, Morin MJ, Chavez A, Hodin RA, Fink MP. Inhibition of inducible nitric oxide synthase ameliorates endotoxin-induced gut mucosal barrier dysfunction in rats. Gastroenterology, 1997; 113:1246-57.

22. Wu B, Iwakiri R, Tsunada S, Utsumi H, Kojima M, Fujise T, Ootani A, Fujimoto K. iNOS enhances rat intestinal apoptosis after ischemia-reperfusion. Free Radic Biol Med, 2002; 33:649-658.

23. Mosmann T. Rapid colorimetric assay for cellular growth and survival: application to proliferation and cytotoxicity assays. J Immunol Methods, 1983; 65:55-63.

24. Sun Z, Wang X, Deng X, Lasson A, Wallén R, Hallberg E, Andersson R. The influence of intestinal ischemia and reperfusion on bidirectional intestinal barrier permeability, cellular membrane integrity, proteinase inhibitors, and cell death in rats. Shock, 1998; 10:203-12.

25. Ogura J, Kobayashi M, Itagaki S, Hirano T, Iseki K. Post-transcriptional regulation of breast cancer resistance protein after intestinal ischemia-reperfusion. Biol Pharm Bull, 2008; 31:1032-1035.

26. Hori S, Ohtsuki S, Tachikawa M, Kimura N, Kondo T, Watanabe M, Nakashima E, Terasaki T. Functional expression of rat ABCG2 on the luminal side of brain capillaries and its enhancement by astrocyte-derived soluble factor(s). J Neurochem, 2004; 90:526-536. 